REVISTA DE DERECHO UNED, NÚM. 14, 2014

\title{
LA SINGULARIDAD DE LOS DAÑOS MEDIOAMBIENTALES. UN ANÁLISIS A LA LUZ DE LA LEY DE RESPONSABILIDAD MEDIOAMBIENTAL EN ESPAÑA
}

THE SINGULARITY OF THE ENVIRONMENTAL DAMAGES. AN ANALYSIS BASED ON THE LAW OF ENVIRONMENTAL LIABILITY IN SPAIN

DANNy Clovis SiaKA

Doctorando en Derecho en la UNED

Resumen: Esta contribución analiza los daños medioambientales a partir de la Ley 26/2007, de 23 de octubre, de Responsabilidad Medioambiental en España, y traza similitudes entre ellos y los clásicos, base de la responsabilidad civil clásica de la que se separa la medioambiental. Dichos daños aparecen como una categoría específica al menos porque su régimen de reparación está esencialmente orientado a la restauración del elemento menoscabado, pudiendo el operador reparar con entrega de suma de dinero sólo cuando la Administración pública haya tomado en su lugar las medidas oportunas para la restauración. Esta característica, además del hecho que los daños medioambientales puedan tomar la forma de amenazas o de riesgos, permite distinguirlos de los clásicos.

Palabras claves: Medio ambiente, daño medioambiental, ecocentrismo, antropocentrismo, responsabilidad medioambiental.

Abstract: This contribution analyses the environmental damages from the elements of definition provided by Law $n .^{\circ}$ 6/2007, of October 23, related to environmental liability in Spain and traces similari- 
ties between them and the classics which are the base of the classical civil liability from which is separated the environmental liability. So, they appear to be a specific issue given, at least, the regime of their repair, essentially orientated toward the reinstatement of the altered natural resource, being possible for the operator to redress by paying a sum of money only when the public Administration has taken appropriate measures at his place. This characteristic, beside the fact that environmental damages can take the form of threats or risks, enables to distinguish them from conventional ones.

Key words: Environment, environmental damage, eco-centrism, anthropocentrism, environmental liability.

Sumario: Introducción. I. Significado del daño medioambiental. I.1. El daño medioambiental entre antropocentrismo y eco-centrismo. I.1 A. La centralidad del ser humano en el daño medioambiental. I.1.B. La naturaleza, punto central del daño medioambiental. I.2. Elementos constitutivos de los daños medioambientales. I.2.A. El cambio adverso de un recurso natural. I.2.B. El cambio mensurable. I.2.C. El carácter significativo del cambio. II. La clasificación de los daños medioambientales. II.2. Clasificación basada en la naturaleza del elemento medioambiental considerado. II.3. Clasificación basada en la manifestación del daño. III. La reparación de los daños medioambientales. III.1. El principio: La restauración. III.2. La excepción: La reparación pecuniaria. Conclusion. Bibliografía.

Recepción original: 10/04/2014

Aceptación original: 14/05/2014

\section{INTRODUCCIÓN}

La rama de la ciencia jurídica que se ocupa del medio ambiente forma también parte de la gran familia del Derecho de daños ${ }^{1}$ dado que la responsabilidad constituye su columna vertebral. Del mismo modo que quien haya causado un daño a terceros debe repararlo, quien ha causado un daño medioambiental debe responder de su actuación. Se trata, en este último supuesto, de la responsabilidad medioambiental que la Ley 26/2007, de 23 de octubre (LRM) no cali-

${ }^{1}$ El denominado «Derecho de daños» aparece como «un pretendido sector autónomo del Ordenamiento Jurídico», que designa a la responsabilidad civil extracontractual; autonomía que carece de relevancia en la práctica, sino, quizás, a nivel didáctico como bien subraya la doctrina. (Ver. LASARTE, C; Derecho de Obligaciones, 12. ${ }^{a}$ ed., Madrid, Marcial Pons, 2008, págs. 282-283). 
fica ni como administrativa, ni como penal, ni como civil. ${ }^{2}$ Sólo regula la «responsabilidad medioambiental», como si se tratara de una categoría especial dentro de la esfera del Derecho de daños. Sin embargo, parece haber optado por la vertiente pública o administrativa, ya que dice en su Preámbulo que la responsabilidad medioambiental que desarrolla se separa de "la responsabilidad civil clásica en la que el conflicto entre el causante del daño y el perjudicado se dirimen en sede judicial». De esta manera, el legislador establece una responsabilidad medioambiental distinta de la responsabilidad civil calificada como "clásica». Frente a esta postura legal, y dado que a raíz de toda responsabilidad se encuentra, mutatis mutandis, el daño, surge la pregunta de saber si el daño medioambiental se distingue por tanto de lo que convendría reconocer como daño clásico. Se trata de saber si el daño medioambiental puede considerarse como una categoría sui géneris de agravio. La respuesta a esta pregunta procederá de un análisis previo del concepto de daño medioambiental (I), seguido de un repaso de su clasificación (II) antes del examen de algunas cuestiones relativas a su reparación (III).

\section{SIGNIFICADO DEL DAÑO MEDIOAMBIENTAL}

La Ley 26/2007, de 23 de octubre, de responsabilidad medioambiental (LRM), tiene entre otros méritos el de definir el daño, en general determinado a partir de situaciones de hecho. A este respecto, y de acuerdo con el apartado 2 de su artículo 2, el daño en general y el daño medioambiental en especial, es «el cambio adverso y mensurable de un recurso natural o el perjuicio de un servicio de recursos naturales, tanto si se produce directa como indirectamente»; incluidos aquellos «que hayan sido ocasionados por los elementos transportados por el aire.» Enumerando los recursos naturales a los que se refiere, menciona a las especies silvestres y a los hábitats, las aguas, la ribera del mar y de las rías, y al suelo. La especial referencia, recogida en el apartado 2 de dicho artículo 2 , invita a analizar al aire como el vector, el vehículo de un daño medioambiental concreto. De este modo, procede matizar la idea según la cual el daño al aire se encontraría excluido, pues o bien el daño medioambiental considerado al final es

2 Tratando de las singularidades del Derecho Ambiental, LozANo CuTANDA observa que tiene ramificaciones en todos los sectores del ordenamiento jurídico, y que, por tanto, se habla tanto del «derecho constitucional del medioambiente», del «derecho ambiental civil», del «derecho ambiental penal», o del «derecho tributario ambiental», entre otros. (Lozano Cutanda, B.; Derecho Ambiental Administrativo, 11. a ed., Madrid, La Ley, 2010, pág. 49). 
la consecuencia de la perturbación del aire ${ }^{3}$, o es la manifestación de la misma. ${ }^{4}$

Dicho lo que precede, conviene determinar el significado del daño medioambiental con referencia a las dos posturas opuestas que son el antropocentrismo y el eco-centrismo (1) y, con referencia al ya mencionado apartado 2 del artículo 2 de la LRM, detenernos ante los elementos o las características que se deben reunir para que se constituya un daño medioambiental (2).

\section{I.1. El daño medioambiental entre antropocentrismo y eco- centrismo}

Desde la Conferencia sobre el Medio Humano, conocida como Conferencia de Estocolmo, celebrada del 5 al 16 de junio de 1972, ${ }^{5}$ la cuestión del medio ambiente está íntimamente vinculada con la calidad de la vida humana en la tierra. De hecho, el principio 1 de la Declaración adoptada al término de dicha Conferencia proclamaba que «el hombre tiene el derecho fundamental a la libertad, a la igualdad y al disfrute de condiciones de vida adecuadas en un medio de calidad tal que permita llevar una vida digna y gozar de bienestar, y tiene la solemne obligación de proteger y mejorar el medio para las generaciones futuras.» Este planteamiento guiará las reflexiones o las producciones normativas sobre el medio ambiente. De manera ilustrativa, tanto el "Informe Brundtland» de 1987, titulado "Nuestro Futuro Común», como la Declaración de Río de 1992, al relacionar el medio ambiente con el desarrollo, recuerdan la centralidad del ser humano en cual-

\footnotetext{
${ }^{3}$ Según se explica, el aire es un «elemento relevante solo en cuanto transmisor de la contaminación (...)» (Ibid., pág. 392). Por tanto, no se trata de una exclusión del aire o de la atmósfera de los elementos medioambientales protegidos o susceptibles de ser objetos de daño, en contra de lo que afirma Esteve PARDo, J.; Ley de responsabilidad medioambiental. Comentario sistemático, Madrid, Marcial Pons, 2008, pág. 30.

${ }^{4}$ Como ocurre con la contaminación acústica, entendida por el artículo 3(d) de la Ley 37/2003, de 17 de noviembre, del Ruido, como «la presencia en el ambiente de ruidos o vibraciones, cualquiera que sea el emisor acústico que los origine, que impliquen molestia, riesgo o daño para las personas, para el desarrollo de sus actividades o para los bienes de cualquier naturaleza, o que causen efectos significativos sobre el medio ambiente.» Así pues, se hablará de la contaminación a partir del momento de la presencia en el ambiente -más bien en el aire- de estos ruidos o vibraciones molestos, o susceptibles de serlo.

${ }^{5}$ Esta Conferencia se reconoce como «un gran hito del derecho internacional del medio ambiente» (LozANo CutANDA, B.; op. cit., pág. 63), como «el pistoletazo de salida para una nueva rama del derecho internacional: el derecho internacional del medio ambiente.» (Lazaro Calvo, T.; Derecho internacional del medio ambiente, Barcelona, Atelier, 2005, pág. 138).
} 
quier política ambiental. A nivel interno español, la Constitución de 1978, en su artículo 45, recoge el derecho-deber al medio ambiente, al proclamar en su apartado 1 que «todos tienen el derecho a disfrutar de un medio ambiente adecuado para el desarrollo de la persona, así como el deber de conservarlo.» En esta lógica de derecho-deber, la cuestión del medio ambiente, bien sea su disfrute como su protección, gira en torno al ser humano, al ciudadano. De este análisis se deduce que el daño medioambiental será aquello que ponga en peligro o menoscabe la calidad del medio, tal que no permita al hombre llevar una vida digna ni gozar de bienestar o, lo que es lo mismo, aquél daño cuya consecuencia sea que el entorno se convierta en lugar inadecuado para el desarrollo de la persona. Por consiguiente, el ser humano está en el centro de la preocupación ambiental. Este antropocentrismo no oculta lo suficiente una tendencia a privilegiar el propio medio ambiente en la política de protección o de defensa de nuestro medio de vida.

\section{I.1.A. La centralidad del ser humano en el daño medioambiental}

La lógica antropocentrista en la aprehensión de las cuestiones relativas al medio ambiente se encuentra ya en la historia de la creación, pues en el Libro del Génesis, el Hombre fue situado en medio de todo lo creado, a cargo de dominar y someterlo. Para cumplir con esta encomienda divina, se puso a actuar hasta hacer peligrar el futuro de su especie. ${ }^{6}$ Por tanto, resulta importante, en la vida en sociedad, que unos y otros respeten este derecho-deber al medio ambiente, en el que tanto el acreedor como el deudor son el ser humano, frente a su prójimo.

Fuera de este ángulo, y desde una postura puramente jurídica, todo lo que contempla, aprehende el Derecho, lo es con respecto al ser humano. Él o la persona, es el único sujeto de derecho, siendo las demás cosas creadas, en realidad, sólo objetos de derecho. Por tanto, no hay otro interés a proteger que el del hombre, ni institución, ni norma que no esté hecha pensando en él. Así, cualquier importancia que se dé a cualquier otra cosa, que tendería a convertirla en sujeto de derecho, lo es sólo en la medida del interés que tendría el Hombre en dicha cosa. ${ }^{7}$ Es decir, como ya hemos indicado, que no hay daño

\footnotetext{
${ }^{6}$ Ver Remond-Goullloud, M.; Du droit de détruire. Essai sur le droit de l'environnement, Paris, PUF, 1989, págs. 11-15.

${ }^{7}$ Ibid., pág. 45.
} 
medioambiental sino en referencia al ser humano, en su incidencia sobre su vida o sus condiciones de vida.

Siguiendo en la misma línea, la relación entre el ser humano y las demás creaturas es la de dominación y de sumisión, cuya forma de expresión en el Derecho es la posesión o la propiedad. Así, no cabe duda que la alteración de cualquier elemento constitutivo del medio ambiente que esté en su posesión o en su propiedad, es susceptible de incidir sobre el conjunto de nuestro entorno, convirtiéndose, en este supuesto, el daño sufrido en daño medioambiental. Por consiguiente, el daño medioambiental puede también apreciarse con respecto a las cosas que estén dentro de la esfera privada de la persona humana.

Pero, y no cabe ninguna duda, el antropocentrismo no excluye el respeto, debiendo el ser humano aprender a contar con las reacciones de la naturaleza y encontrar su lugar en la cadena de los seres vivos. ${ }^{8}$ Lo es tanto que "la supervivencia de la especie humana depende de que las que nos acompañan también se salven.»9

\section{I.1.B. La naturaleza, punto central del daño medioambiental}

La postura eco-centrista encierra una contradicción en la medida que pretende, a efectos de la protección del medio ambiente, reconocerle una cierta subjetividad jurídica, pero dejando todavía en manos humanos su tutela efectiva. ${ }^{10}$ Aquí, parece oponerse el interés humano y un interés del medio ambiente. Expresa una cierta relación conflictual entre el hombre y el entorno que sería tan frágil que cualquier actuación de aquél lo pondría en peligro. ${ }^{11}$ Se trata por tanto de llegar a un "equilibrio de la naturaleza», que precisa del respeto del hombre $^{12}$ que parece «insostenible», "consumista y acaparador genéticamente», parte de las «biomasas humanas alienadas y consumistas, que se niegan voluntariamente a la moderación, al conocimiento y la cultu$\mathrm{ra}(\ldots){ }^{13}$

\footnotetext{
${ }^{8}$ Ibid., pág. 46.

${ }^{9}$ Loperena Rota, D.; Los principios del Derecho ambiental, Madrid, Civitas, 1998, pág. 31.

${ }^{10} \mathrm{Idem}$.

${ }^{11}$ Ver Craig, J. R.; Vaughan, D.; Skinner; B. J.; Recursos de la tierra y el medio ambiente, 4. ${ }^{\mathrm{a}}$ ed., Madrid, UNED/PEARSON, 2012, pág. 108.

${ }^{12}$ Ver G. A. Theodorson; Estudios de ecología humana, vol. 1, Barcelona, Editorial Labor S. A, 1974, pág. 46.

13 Vozmediano, J.; El hombre insostenible, Sevilla, Universidad de Sevilla, 2012, pág. 83.
} 
Esta postura eco-centrista, con su contradicción, es la de la Ley 26/2007, de 23 octubre, de responsabilidad medioambiental (LRM), cuyo artículo 2 , inciso 1 , entiende por daños medioambientales, los «daños a» los elementos medioambientales que se enumera. ${ }^{14} \mathrm{El}$ interés por el ser humano aparece, en filigrana, en la definición del concepto de reparación, sobreentendiéndose que ésta tiene como finalidad preservar la salud humana (art. 2-20). Además, al excluir de su ámbito de aplicación los daños a particulares -que sólo están contemplados como causantes en su calidad de operadores-, se mantiene, desde nuestro punto de vista, en esta misma lógica. Esta subjetivización del medio ambiente va a conferir la consideración de daños medioambientales, a tenor de la LRM, a aquellos que tengan al ambiente en la condición de sujeto de derecho, de víctima. Esto da por tanto cierta particularidad al daño medioambiental cuya constitución requiere la reunión de unos criterios.

\section{I.2. Elementos constitutivos de los daños medioambientales}

Además de especificar en su apartado 1, los elementos sobre los que pueden recaer los daños medioambientales, el artículo 2 de la LRM define al daño como "el cambio adverso y mensurable de un recurso natural o el perjuicio de un servicio de recursos naturales, tanto si se produce directa como indirectamente.» ${ }^{15}$

\section{I.2.A. El cambio adverso de un recurso natural}

El cambio adverso expresa la idea de la trasformación negativa, del deterioro experimentado por el recurso natural considerado, a consecuencia del suceso dañoso. Podrá este cambio tocar, por ejemplo, a la estructura del elemento ambiental o a su función.

El cambio material o estructural de un recurso natural versaría sobre la estructura o las características de unas especies silvestres, de las hábitats, sobre el «estado ecológico, químico y cuantitativo» de las

${ }^{14}$ Como señala Esteve PARdo, «la posición de las víctimas vienen a ocuparla una serie de bienes y recursos naturales (...) que, obviamente, no son personas, ni pueden actuar como tales.» (EsTeVe PARDo, J.; op. cit., pág. 10).

${ }^{15}$ La definición del «daño» por la LRM es en sí una originalidad ya que, como observaba EgEA FernANDEZ, «los daños se tratan como una cuestión de hecho que debe ser objeto de prueba, por lo que deberá estarse a cada caso»; pues el derecho civil no lo define en ninguno de sus preceptos. (EGEA FERNÁNDEZ, J.; «Relaciones de vecindad, desarrollo industrial y medio ambiente», en EsTEVE PARDO, J. (Coord.); Derecho al medio ambiente y administración local, Madrid, Civitas, 1996, pág. 69). 
aguas, en la «integridad física y adecuada conservación» de la flora, del mar o de las rías. ${ }^{16}$ También podrá apreciarse el cambio adverso a partir de la posibilidad para el recurso en cuestión, de cumplir o no con su función. Es la línea en la que va el legislador cuando define a los daños a las especies silvestres y a los hábitats como "cualquier daño que produzca efectos adversos significativos en la posibilidad de alcanzar o de mantener el estado favorable de esos hábitat o especies.» Es decir que el daño no se materializa aquí por el «cambio adverso» en sí, sino por el efecto adverso de dicho cambio en la función del elemento ambiental considerado, pues habrá daño cuando dicho recurso ya no pueda alcanzar o mantener "el estado favorable de conservación de esos hábitat o especies.»

De manera general, la idea del cambio funcional se encuentra en el centro de toda la filosofía del daño medioambiental. El cambio material o estructural toma relevancia sólo cuando acaba alterando la función de un elemento medioambiental determinado, el suelo por ejemplo, dada su importancia tanto para el ser humano como para las demás especies naturales. ${ }^{17}$ Estructural o funcional, el cambio adverso debe ser, según la ley, mensurable.

\section{I.2.B. El cambio mensurable}

La exigencia de que el cambio sea mensurable se efectúa, sin duda, en la perspectiva de la reparación del daño medioambiental. La cuestión es, por tanto, la de saber cómo se puede, de manera objetiva, medir el cambio.

En primer lugar, para mensurar al cambio, habrá que tener en cuenta el estado inicial del valor protegido y aquél en el que se encuentre en un momento determinado, siendo la variación entre los dos estados el dato que, según interpretación de la ley, habrá de ser mensurado. En este sentido, hay elementos medioambientales que, por su naturaleza, ofrecen una clave para una mensuración objetiva del cambio adverso eventualmente experimentado. Así, por ejemplo, la disminución de las cantidades del agua de un lago o de un estanque se apre-

${ }^{16}$ Nótese que los daños al suelo se encuentran contemplados desde la perspectiva del riesgo que, como se verá, no supone ningún cambio presente. Además, y teniendo en cuenta la definición hecha más arriba del daño medioambiental, se entiende, y esto lo subraya la propia Ley 26/2007, de 23 de octubre, que este cuerpo legal no aprehende nada más que a los daños materiales, y, más precisamente, los daños a los propios elementos ambientales.

${ }^{17}$ En esta línea: Craig, J. R.; Vaughan, D.; Skinner, B. J.; op. cit., pág. 480. 
ciará a partir de la variación de la superficie de su lecho. Del mismo modo, a nivel cualitativo, el cambio adverso se podrá determinar a partir de las cantidades o del porcentaje en el cual se calcula la presencia de sustancias tóxicas, en comparación con el estado que debe presentar un determinado recurso natural en condiciones normales.

En segundo lugar, la mensurabilidad objetiva se referiría a la posibilidad de constatar, objetivamente, la efectividad del cambio adverso experimentado por un interés o un recurso protegido. En este sentido se deberá entender la inclusión expresa de los daños con efectos demostrados en la salud humana en la categoría de los daños significativos. ${ }^{18}$ Hablando de los daños con efectos demostrados en la salud humana, cabe señalar que no siempre los efectos pueden ser idénticos, con lo cual es difícil lograr en la materia una unificación de criterios que ayude a evitar por completo la subjetividad a la hora de apreciar el alcance del cambio.

Desde nuestro punto de vista, la mensurabilidad objetiva no es una característica de todos los daños medioambientales, lo que hace que los cambios objetivamente mensurables no sean los únicos susceptibles de reparación. Esto significa que, si la naturaleza del elemento ambiental considerado no lo permite, la apreciación de la mensura incumbirá, en caso de conflicto, al juez. Esta postura invita a preguntarse por el interés jurídico de la exigencia según la cual el cambio adverso ha de ser mensurable para que se encuentren reunidos todos los criterios de definición del daño en general, y del daño medioambiental en especial. Además debemos plantearnos también si esta exigencia tiene carácter imperativo.

Si se requiere que el cambio o el efecto adverso sea mensurable, es para poder determinar, con la mayor objetividad posible, su efectividad. Así, no es un criterio imprescindible para la constitución del daño, ya que, en caso de no poder ser objetivo, su alcance, como ya queda señalado, será determinado por el juez. Así, la exigencia sólo pretende contribuir a la valoración del daño, paso previo a su reparación y, por ende, permite determinar en qué medida sería significativo el cambio adverso.

\section{I.2.C. El carácter significativo del cambio}

Lo que parece llamativo es que la exigencia sobre el carácter significativo del cambio no figura en la definición del daño por la LRM

${ }^{18}$ Anexo I - 2, LRM. 
sino, en la descripción de los elementos que debe reunir para constituirse. ${ }^{19}$

En efecto, con referencia a esta última idea, el legislador indica que «el carácter significativo de esos efectos se evaluará en relación con el estado básico, teniendo en cuenta los criterios expuestos en el anexo 1.» ${ }^{20}$ Así, en la exigencia del carácter significativo del cambio subyace la idea del criterio de valoración del daño. Además, implica que sólo sean considerados, a efectos de responsabilidad medioambiental, aquellos daños que supongan una real alteración del recurso, y no estas «normales incomodidades asociadas a la convivencia»;21 idea ya expresada por la jurisprudencia. ${ }^{22}$ Esto significa que, a pesar de la indicación, en el anexo 1 de la Ley 26/2007, de criterios de apreciación del carácter significativo, pueden carecer de una cierta objetividad.

Así, pese a su indudable relevancia, la exigencia según la cual el cambio debe ser significativo adolece de dos límites que son motivos de críticas. Uno versa sobre la determinación del carácter significativo, mientras que otro versa sobre el abanico de daños medioambientales susceptibles de ser recogidos ateniéndose a este criterio.

En efecto, y esto por una parte, la enumeración en el anexo 1 de la LRM, de los criterios de apreciación del carácter significativo no logra determinar cómo, objetivamente, se podrá decir, de manera constante, que tales cambios son significativos y que tales otros no lo son. Sin duda, se tendrá que decidir de manera casuística. ${ }^{23}$

Por otra parte, es posible pensar que algunos daños que no pueden calificarse como «significativos» de acuerdo con la ley, queden sin

${ }^{19}$ Para ilustrar esto, podemos citar a los distintos incisos del apartado 1 del artículo 2 de la LRM, dónde se habla, repetitivamente, de «efectos adversos significativos.» Esto aparece en la definición de los daños a las especies silvestres y a los hábitats (inciso a), de los daños a las aguas (inciso b), de los daños a la ribera del mar y a las rías (inciso c). A la hora de aprehender a los daños al suelo, recogidos en el inciso d, la Ley 26/2007, en vez de hablar de "efectos adversos significativos", habla de "riesgo significativo de que se produzcan efectos adversos.» Es decir que no se requiere aquí que las infiltraciones o los vertidos contaminantes sean coetáneos de los efectos adversos.

${ }^{20}$ Artículo 2, apartado 1, inciso a, LRM.

${ }^{21}$ Cordero Lobato, E.; «Derecho de daños y medio ambiente», en OrTEga Alvarez, L. (Dir.), Lecciones de Derecho del Medio Ambiente, Valladolid, Lex Nova, 1998, pág. 439. - Aquí, la idea va asociada a la del abuso de derecho.

${ }^{22}$ STS, 1. ${ }^{\text {a }} 14$ de abril 1962 (RA 2028). Por tanto, la determinación del umbral de tolerabilidad debe incumbir a los tribunales. (LlodRa GRIMALT, F.; Lecciones de Derecho Ambiental Civil, Palma, Universitat de les Illes Balears, 2008, pág. 100.)

${ }^{23}$ Es verdad, los otros criterios parecen de fácil aplicación; pero habrá que puntualizarse, por obra del juez o de la Administración, los elementos requeridos a tal efecto. 
reparación, con las correspondientes consecuencias tanto a nivel global -considerándose el medio ambiente como interés global- como a nivel individual, o sea privado. Lo que precede deriva del hecho que la Ley 26/2007 está más pensada para la defensa o la protección del interés difuso medioambiental. ${ }^{24}$

Tales son los elementos que permiten constituir el daño medioambiental que tiene también cierta importancia a nivel taxonómico.

\section{LA CLASIFICACIÓN DE LOS DAÑOS MEDIOAMBIENTALES}

La aproximación de los daños medioambientales desde una perspectiva taxonómica presenta un doble interés teórico y práctico. Sobre el plan teórico, participa de la cuestión de saber lo que podría constituir la eventual singularidad de aquellos daños. A nivel práctico, participa del esfuerzo de lograr la reparación de los daños medioambientales, que presupone que tengan algún grado de «madurez», de efectividad. Sólo se recogerán aquí tres criterios de clasificación, que no pretenden dar cuenta de toda la cuestión. Por esto convendría, antes, referirnos a la distinción entre daños patrimoniales y daños extrapatrimoniales, ${ }^{25}$ para observar que los segundos carecen de carácter medioambiental, ${ }^{26}$ a diferencia de los primeros, ya que algunos elementos susceptibles de ser objeto de daño medioambiental pueden ser de propiedad privada, es decir formar parte de un patrimonio privado, con su correspondiente valor económico. ${ }^{27}$ También señalamos

${ }^{24}$ Es lo que indica el artículo 3 (3) de la LRM. Así se explica también la exclusión del ámbito de aplicación de esta ley los daños a particulares o a sujetos identificados; a menos, como se dice en su Preámbulo, que el daño haya recaído sobre un bien que tenga la condición simultánea de bien medioambiental y de bien patrimonial o de titularidad privada.

${ }^{25}$ Según indica Alvarez Vigaray, los daños extrapatrimoniales o no patrimoniales se resumen en los daños morales que son, además, una forma de denominarlos. (ALVAREZ Vigaray, R.; La responsabilidad por daño moral»; Anuario de Derecho Civil, 1996, págs. 85-86) - Sobre la cuestión, y más extensamente, ver P. MARTINEZ EsPIN; El daño moral contractual en la Ley de propiedad intelectual, Madrid, tecnos, 1996, págs. 42-44.

${ }^{26}$ Es así porque recaen sobre un interés humano no económico y jurídicamente protegido, y que no es susceptible de equivalencia o valoración pecuniaria. En este sentido: NaveIra Zarra, M. M.; El resarcimiento del daño en la responsabilidad civil extracontractual, Madrid, Editoriales de derecho Reunidas, 2006, pág. 102. En la misma línea: SANTOS BRIZ, J.; La responsabilidad civil. Derecho sustantivo y Derecho procesal, 7. ${ }^{\mathrm{a}}$ ed., Madrid, Ed. Montecorvo, 1993, pág. 162.

${ }^{27}$ Sobre la cuestión: AlbaladeJo, M.; Derecho Civil I, 15. a ed, Barcelona, J. M. Bosch editor, 2002, págs. 506-508. 
aquí que los daños medioambientales, además de ser continuados -como algunos daños clásicos- son en general colectivos. ${ }^{28}$

\section{II.1. Clasificación basada en la certeza del daño}

La clasificación basada en la certeza del daño insinúa la distinción entre daños presentes y daños futuros; entre daños ciertos y daños probables, entre daños ciertos y los denominados por la LRM como los «riesgos de daño».

En efecto, la propia LRM, al contemplar los supuestos de «riesgos de daño», deja ver que los daños medioambientales pueden ser tanto presentes como futuros o probables. Así, a efectos de la reparación, se requiere que la ocurrencia del daño tenga un cierto grado de probabilidad, con el fin de no cargar injustamente algunos agentes jurídicos con la reparación de un daño inexistente, ficticio o inconsistente $\mathrm{y}$, también, de evitar el consiguiente enriquecimiento injusto del acreedor de la reparación. ${ }^{29}$

Por tanto, se dirá del daño que es cierto cuando se haya producido y, como manifestación, se haya experimentado un cambio adverso y mensurable del elemento protegido. Sin embargo, no es necesariamente el que ya exista y cuya mensura se tenga, sino, también aquél que sin falta ocurrirá, aunque todavía sea difícil tener su valoración exacta. ${ }^{30}$ De este modo se distingue el daño cierto del daño meramente eventual. ${ }^{31}$

${ }^{28}$ Blasco Esteve, A.; «Medio ambiente y responsabilidad», en Esteve Pardo, J. (Coord.); Derecho del medio ambiente..., op. cit., pág. 629.

${ }^{29}$ Ver, en este sentido, LASARTE, C.; op. cit., pág. 290: La posibilidad de equiparar la reparación de un daño futuro con un enriquecimiento sin causa a la víctima no obsta, afirma él, a que «la sentencia liquidadora del daño pueda tener en cuenta también a daños futuros si éstos pueden cuantificarse y, simultáneamente, constituyen una derivación o prolongación inevitable, directa y cierta del daño ya acaecido.» A nuestro modo de ver pretender reparar en el presente a daños futuros requiere que se abra una ventana a la posibilidad de proceder más tarde, después de que el daño se haya efectivamente producido, a una revaloración del agravio, para aprehenderlo en su dimensión real, determinar con exactitud su alcance y la correspondiente reparación, para evitar injusticia al causante o a la víctima, según el caso.

${ }_{30}$ "Se trata de acometer un juicio de probabilidad o verosimilitud en virtud del cual se viene a establecer la certeza de un efecto que, aun no habiendo ocurrido todavía, la regla de la experiencia común permite augurar que ocurrirá.» (Yzouierdo TolsAda, M.; Sistema de responsabilidad civil, contractual y extracontractual, Madrid, Dykinson, 2001, pág. 148.)

${ }^{31}$ Ibid., p. 149. - En el mismo sentido, se sostiene que «la certeza del daño no debe de confundirse con su actualidad. Permite sólo excluir de los daños resarcibles los daños 
El daño probable aparece como otra forma de denominar al daño incierto. La probabilidad puede resultar de diversas circunstancias de las que podemos mencionar la falta de contemporaneidad entre el hecho dañoso y la manifestación completa del daño, y entre el hecho dañoso y la víctima. Así, y por una parte, la incertidumbre estriba en el hecho que, en el momento determinado, no se puede saber si habrá o no cambio en el recurso natural considerado; si tal cambio será adverso o no, si tal cambio, de ser adverso, será significativo, producirá efectos significativos o no. ${ }^{32}$ Por otra parte, y al igual que en la primera circunstancia, la incertidumbre procede de que un comportamiento susceptible de causar daño pueda tener consecuencias efectivas sólo al cabo del transcurso de un periodo de tiempo más o menos largo, no siendo cierto que tal comportamiento produzca un daño, ni que el agravio sea la consecuencia de dicho comportamiento, ni que la víctima sea quien se veía antes como tal. ${ }^{33}$

Estas dos circunstancias plantean la cuestión de los daños futuros que, sí, son resarcibles, a condición que la incertidumbre no sea absoluta. En efecto, el daño probable o incierto recoge también la figura de la amenaza, del riesgo. ${ }^{34}$ A nuestro modo de ver, la apreciación de la probabilidad dependerá de qué tipo de consecuencias el suceso haya causado en el pasado y, también, de cada circunstancia.

\section{II.2. Clasificación basada en la naturaleza del elemento medioambiental considerado}

Después de aludir a la clasificación en base al concepto de patrimonio, se trata aquí de determinar los daños medioambientales se-

eventuales o temidos.» (Busto, LAGo J. M.; La antijuridicidad del daño resarcible en la responsabilidad civil extracontractual, Madrid, Tecnos, 1998, pág. 73.).

${ }^{32}$ A este respecto, podemos emplear, con YzQuIERdo Tolsada la expresión «lesión o menoscabo con proyección hacia el futuro", que considera como reparable. (Id.).

${ }^{33}$ Ver Egea FeRnandeZ, J.; op. cit., pág. 70.

${ }^{34}$ Por esto, en el inciso d) del apartado 1 del artículo 2 de la LRM, el legislador define el daño al suelo como «cualquier contaminación del suelo que suponga un riesgo significativo de que se produzcan efectos adversos para la salud humana o para el medio ambiente (...).» Lo que convendría destacar aquí es el carácter significativo del riesgo, ya que el legislador entiende por el riesgo la «función de probabilidad de ocurrencia de un suceso y de la cuantía del daño que puede provocar». De este modo, para que el riesgo pueda tener un efecto jurídico en término de resarcimiento, ha de ser significativo, ha de tener gran probabilidad de ocurrir. Dicho esto, la cuestión estriba en el hecho de saber cómo apreciar la probabilidad susceptible de conferir al riesgo un carácter significativo y, por lo tanto, de convertirlo en una circunstancia equiparable con el daño cierto. 
gún que tengan un carácter material o no. Por tanto se distinguirá entre los daños materiales y los daños inmateriales.

Así, con la asimilación de los daños medioambientales a los daños materiales se pretende hacer referencia a esta categoría de daños que recaiga o afecte a un elemento físico constitutivo del medio ambiente, susceptible de ser calificado como material. Se trata de bienes o elementos que tengan una corporalidad, o sean susceptibles de tenerla. Son, en principio, aquellos que sean físicos y visibles; que se caractericen por elementos objetivos necesarios para su identificación. En esta categoría, y permaneciendo en lo referente al medio ambiente, podemos mencionar a los especímenes de una especie, que contribuyen a la formación de la fauna; a la vegetación, digamos los árboles de un bosque que, en cuanto a ellos, forman parte de la flora. En efecto, conviene recordarlo, el medio ambiente no existe en sí, sino que es un todo que se aprehende desde una perspectiva sistémica. ${ }^{35}$

Los daños materiales, por consiguiente, recaen sobre un bien mueble o inmueble, causando su modificación, su transformación o su desaparición. Teniendo en cuenta la existencia en los bienes muebles de una subdivisión entre bienes corporales y bienes incorporales, la cuestión que se puede plantear aquí es la de saber si en los daños materiales entran tanto los que afecten a bienes corporales como los que afecten a bienes incorporales. ${ }^{36}$

Del mismo modo que los daños extrapatrimoniales recaen sobre bienes que no pueden ser objeto de una valoración pecuniaria, se podría decir que los bienes inmateriales o incorporales escapan, stricto sensu, a la misma valoración. De esta manera, se asimilarían los primeros con los daños inmateriales. Pero, en realidad, existen bienes incorporales susceptibles de valoración pecuniaria. Es el caso del fondo de comercio. ${ }^{37}$ Esto significa que también carece de nitidez el

35 Véase Martin Mateo, R.; Manual de Derecho Ambiental, Cizur Menor, Aranzadi, 2003, pág. 23-25.

${ }^{36}$ Se entiende que, de un cierto modo, se puede asimilar los calificativos «materiales» y "corporales», para deducir que los daños materiales son los que recaen sobre bienes corporales. Si se opera una distinción entre daños y perjuicios para entender a estos últimos como las ganancias dejadas de obtener y los primeros como «pérdida por efectiva disminución patrimonial» (STS, Sala 1. ${ }^{a}$ de 10 de enero de 1979 (RJ 1979/18), sí que se podría decir que los daños sólo afectan a los bienes corporales, mientras que los daños inmateriales afectarían a bienes incorporales.

${ }^{37}$ Se entiende, según una opinión doctrinal como «la plusvalía derivada de la organización de los elementos de toda clase que componen el establecimiento comercial.» (A. ROJO; «El establecimiento comercial»; en MEnEndeZ, A. (Dir.); Lecciones de derecho mercantil, 7. ${ }^{a}$ ed., Cizur Menor, Aranzadi, 2009, págs. 89-90.) De estos elementos se 
criterio de distinción basado en la materialidad o la inmaterialidad del objeto o del elemento alterado. ${ }^{38}$

Aplicada esta clasificación dualista al daño medioambiental, se debe observar que los elementos constitutivos del entorno natural pueden ser materiales o inmateriales. Por esto, los daños medioambientales pueden ser materiales (como los daños a los especies y a los hábitats) o inmateriales (como los daños por alteración de la calidad del aire debida a los elementos que transporta, que pueden ser los ruidos o los olores excesivos). ${ }^{39}$

\section{II.3. Clasificación basada en la manifestación del daño}

La toma en consideración del alcance del daño permite distinguir, además de los daños individuales y los daños colectivos, los presentes y los futuros, los instantáneos y los continuados, asimismo como los denominados «daños por contaminación» de los llamados «daños ecológicos». ${ }^{40}$ Sin necesidad de exponer sobre estas distintas categorías, sólo observaremos que la categoría daños por contaminación recoge un amplio abanico de daños causados al medio ambiente, pues se refiere a la contaminación de sus elementos constitutivos sus-

puede destacar, hablando de elementos incorporales, a la clientela y la capacidad de producción. (Id.).

${ }^{38}$ Aunque la jurisprudencia haya insinuado una clasificación de los daños inmateriales entre daños corporales y daños morales. (Ver STS, $2 .^{a}$ de 10 de noviembre de 1979 [RA 3880]). Debemos observar que es difícil contemplar un daño moral medioambiental, pues el interés moral sería, en general, consustancial a un daño personal o corporal y, en cierta medida, material. A nuestro juicio, en materia medioambiental, se concibe difícilmente un daño moral autónomo. En esta línea, CANE estima que esta categoría de daños, ocasionados a los seres humanos y «derivados de la imposibilidad de seguir usando o disfrutando de un elemento del medio ambiente con fines recreativos, o bien resultantes de saber que dicho elemento ha sido dañado o destruido,» no deben ser reparados, dada la escasez de los recursos en nuestro mundo, y el carácter ilimitado de las necesidades humanas de carácter recreativo, estético e intelectual. (CANE, P.; «Indemnización por daños medioambientales»; Anuario de Derecho Civil, t. III, Fasc. III, Jul.- Sept. 2000, pág. 838.). Desde nuestro punto de vista, convendría distinguir caso por caso, en vez de generalizar la solución propuesta por el autor citado. En efecto, no se niega en sí el daño moral derivado de la alteración de un elemento constitutivo del medio ambiente.

${ }^{39}$ Son los supuestos de la contaminación acústica y la contaminación odorífera, a los que se puede sumar la lumínica, que no tienen ninguna materialidad, ningún soporte material.

${ }^{40}$ Estas características no son exclusivas a los daños medioambientales. Sólo es llamativa la distinción entre daños por contaminación y daños ecológicos que, además, parecen categorías propias a los daños medioambientales. 
ceptibles de incidir sobre la vida humana (de acuerdo con la postura antropocentrista).

Por su parte, los llamados daños ecológicos se oponen a los denominados daños típicos, ${ }^{41}$ y se entienden como daños determinados por la alteración ecológica o la destrucción de elementos naturales de titularidad común. ${ }^{42}$ En la misma línea también se entiende por daños ecológicos aquellos sufridos por el medio ambiente que, como consecuencia de un accidente causado por la mano del hombre, ve afectado su equilibrio natural. ${ }^{43}$ En una y otra definición, lo que se destaca es que la calificación de un daño como ecológico depende de la titularidad común del interés lesionado, del carácter global de dicho interés, por oposición a los intereses individuales.

Como se debe observar, el interés privado o individual no es siempre opuesto al interés común. Así, no sólo que los daños, en principio "ecológicos», son susceptibles de rebotar para afectar a intereses individuales, sino que el individuo puede encontrar un interés legítimo en un bien o interés común, pues del mismo modo que los intereses individuales contribuyen a la formación de los intereses colectivos, el individuo es partícipe de la comunidad. ${ }^{44}$

Así, los daños ecológicos o ecológicos $\operatorname{puros}^{45}$ nos parecen una categoría cuestionable respecto a la de los daños por contaminación. ${ }^{46}$ La clasificación a la que acabamos de proceder no es exclusiva a los daños medioambientales. Más bien, permite aprehenderlos de la misma manera que a los daños clásicos que también pueden ser con-

${ }^{41}$ Definidos como daños al medio ambiente, que van acompañados de un daño a tercero, a su persona o a su propiedad. «Se trata de daños medioambientales individuales que se incardinan en la protección dispensada por el Código Civil a la persona y a la propiedad.» (LlodRA GRIMALT, F.; op. cit., pág. 93).

${ }^{42}$ Idem.

43 Diez-Picazo Gimenez, G.; op. cit., Id.

${ }^{44}$ Sobre los intereses legítimos, véase Naveira ZarRa, M. M.; op. cit., pág. 49.

${ }^{45}$ Ruda Gonzalez, A.; El daño ecológico puro, Cizur Menor, Thomson Aranzadi, 2008, págs. 32-34 - La cuestión que se podría también plantear aquí sería la de saber si se puede, en la categoría de los daños ecológicos, distinguir entre los daños ecológicos puros y los daños meramente ecológicos; pues lo ecológico lleva implícito al medioambiental con lo cual, en principio un daño medioambiental es desde luego ecológico porque afecta de un cierto modo al ecosistema.

${ }^{46}$ Esto porque, como ya apuntamos, insinuar o plantear que el medio ambiente es susceptible de sufrir daños expresa su personificación y puede resultar contraproducente a la hora de contemplar su protección eficaz. En efecto, y desde nuestro punto de vista, bien sea desde la perspectiva administrativa, la perspectiva civil, como desde la perspectiva penal, la protección se analiza en consideración del individuo tomado en su unidad, su «individualidad», o tomado a partir de su vinculación con la colectividad con la que interrelaciona. 
tinuados, presentes, ciertos o probables, materiales o inmateriales, recaer o no sobre un elemento natural, tener una dimensión patrimonial o no. Vistos así, incluso con sus especiales características, ${ }^{47}$ no tienen ningún carácter singular u original, a menos que se encuentre en las modalidades de su reparación.

\section{LA REPARACIÓN DE LOS DAÑOS MEDIOAMBIENTALES}

Los daños medioambientales, como cualquier daño jurídico, son reparables. En realidad, existe una variedad de términos para denominar estas acciones o estas diligencias que ha de efectuar el responsable del daño para borrar o aminorar sus manifestaciones, o corregir sus consecuencias en el interés protegido, en quién o en el patrimonio de quién lo hubiera sufrido. Se habla tanto de reparación, de resarcimiento, o de restauración. El concepto de reparación, a pesar de los matices que parece encerrar, aparece como uno genérico, para denominar estas distintas modalidades. ${ }^{48}$ Sin embargo, se debe observar que, a diferencia del daño clásico, el medioambiental recae sobre un bien de disfrute común, de interés común, o un bien de titularidad privada, pero susceptible de afectar al interés común, por ser un elemento constitutivo del medio ambiente. Por esta razón la reparación del daño medioambiental está en principio encaminada a restaurar el valor menoscabado. Por tanto, siendo la restauración el principio, el sufrago de un importe, o sea la reparación pecuniaria, sólo es una excepción, a diferencia de lo que ocurre con los daños clásicos dónde las partes interesadas pueden, mediante convenio, decidir la forma en la que se logrará la reparación del agravio. ${ }^{49}$

\section{III.1. El principio: La restauración}

La LRM sitúa claramente la restauración como forma primera de reparación de los daños medioambientales. En efecto, según lo dispuesto por el artículo 20 de esta normativa legal, el operador deberá, una vez que se hayan producido daños medioambientales, adoptar, «sin demora y sin necesidad de advertencia, de requerimiento o de acto

${ }^{47}$ Blanco Esteve, A.; op. cit., idem.

${ }^{48}$ Sobre estos matices, ver DE LA VEGA GaRcia, F. L.; Responsabilidad civil derivada del producto defectuoso. Un estudio de la Ley 22/1994 en el sistema de responsabilidad civil, Madrid, Civitas, 1998, pág. 121 y DE ÁNGEL YAGÜEZ, R.; Algunas previsiones sobre el futuro de la responsabilidad civil, Civitas, Madrid, 1995, pág. 108.

${ }^{49}$ LASARTE, C.; op. cit., pág. 356. 
administrativo previo (...) todas aquellas medidas provisionales necesarias para, de forma inmediata, reparar, restaurar o reemplazar los recursos naturales y servicios de recursos naturales dañados (...)», entendido que deberá también someter «a la aprobación de la autoridad competente una propuesta de medidas reparadoras de los daños medioambientales causados (...)», de acuerdo con lo establecido por la ley.

Lo que conviene observar aquí es que la ley no ofrece a este nivel ninguna alternativa a la restauración que aparece como la idea de fondo que vehiculan los tres verbos empleados, y que son los siguientes: «reparar, restaurar o reemplazar. ${ }^{50}$ Las tres modalidades de reparación especificadas en el Anexo 1 abundan en este sentido. Esto se explica por el hecho que la protección del medio ambiente es aquí el interés que toma más relevancia. El preámbulo de este texto legal lo subraya indicando que «al poner el énfasis en la restauración total de los recursos naturales y de los servicios que prestan, se prima el valor medioambiental, el cual no se entiende satisfecho con una mera indemnización dineraria.» De esta manera, el pago de una cantidad de dinero por el operador causante del daño medioambiental debe entenderse sólo como una modalidad excepcional de reparación. ${ }^{51}$

\section{III.2. La excepción: La reparación pecuniaria}

En la responsabilidad civil clásica, la entrega de una cantidad de dinero en concepto de reparación de un agravio causado, toma en general la forma de una indemnización que difícilmente logrará poner al agraviado en su situación antes de la producción del daño. Se entiende que la parte que no se consigue satisfacer, por cuanto no sea desproporcionada y no empobrezca al agraviado, corresponde a las normales incomodidades que ha de soportar cada persona por el hecho de vivir en sociedad..$^{52}$ En la responsabilidad medioambiental en cambio, a pesar de un cierto eco-centrismo, no se pretende personificar al medio ambiente para convertirlo en acreedor de una indemnización, sino se pretende sólo que quien haya causado el daño sufra-

${ }^{50}$ La LRM, que transpone al Derecho español la Directiva 2004/35/CE, del Parlamento y del Consejo, de de 21 de abril de 2004, sobre responsabilidad medioambiental en relación con la prevención y reparación de daños medioambientales, sigue así la línea marcada por el Convenio sobre la responsabilidad civil por daños causados por actividades peligrosas para el medio ambiente (Lugano, 21 de junio de 1993), en su artículo 2 (8), dónde habla de medidas de restauración («measures of reinstatement»). Ver, en esta línea. Loperena Rota, D; op. cit., pág. 74).

${ }^{51}$ En esta misma línea: Lozano Cutanda, B.; op. cit., págs. 402-404.

${ }^{52}$ Ver Cordero Lobato, E.; op. cit., Id. 
gue los costes de reposición de lo menoscabado, en el interés de la comunidad. Esto es el sentido de la regla de quien contamina paga, sobre la que se apoya la responsabilidad medioambiental desarrollada por la LRM. ${ }^{53}$

Por tanto, se acudirá a la reparación pecuniaria sólo cuando la Administración haya procedido previamente a la restauración en el lugar del operador responsable. ${ }^{54}$ En esta circunstancia, la Administración se subroga al operador en su obligación de restaurar al elemento medioambiental menoscabado, incluso cuando aquél no haya podido ser identificado. ${ }^{55}$ Por consiguiente, son, de manera general, dos los supuestos en los que el operador repara el daño con entrega de una suma de dinero: el de reparación urgente y provisional para evitar que el daño se agrave, y el de reparación forzosa. La entrega dineraria será entonces para compensar la Administración, a quien incumbe la responsabilidad de velar por la protección del medio ambiente y quien debe, por consiguiente, tomar cualquier medida apropiada para lograrlo. Esta tutela administrativa sobre el medio ambiente permite también hacer efectiva otra dimensión, no menos importante, de la responsabilidad medioambiental, que es la prevención del daño. Esto significa que, a diferencia de los daños clásicos, la falta o el incumplimiento de medidas preventivas es susceptible de dar lugar a responsabilidad, ya que puede ser causa de una amenaza de daño.

\section{CONCLUSIÓN}

La Ley de responsabilidad medioambiental (LRM), de transposición en España de la Directiva 2004/35/CE, de 21 de abril de 2004, establece un régimen de responsabilidad tutelada por la Administración pública, que se separa de la responsabilidad civil clásica, y que no es penal. Con este enfoque, se da más importancia al medio ambiente y, sin duda, se refuerza su protección. Si fuera sólo por esta razón, quizás no habría sido necesario desarrollar esta responsabili-

${ }^{53}$ Sobre la cuestión: Viguri Perea, A.; Globalización y defensa del medio ambiente en el derecho privado: aplicación del principio "quien contamina paga» y régimen de la responsabilidad civil objetiva. Derecho español, europeo, norteamericano y japonés; Madrid, Fundación Registral; Colegio de Registradores de la propiedad y mercantiles de España, 2009, págs. 339-364.

${ }^{54}$ Es una de las potestades administrativas en materia de reparación de daños medioambientales, «ejecutar a costa del sujeto responsable las medidas reparadoras (...).» (art. 21- e, LRM).

${ }^{55}$ Estos supuestos vienen contemplados en los artículos 23 y 47 de la LRM. 
dad especial, por lo menos por el carácter especial de la normativa correspondiente. Acaso para justificar que la responsabilidad medioambiental sea especial, los daños medioambientales debían constituir una categoría sui géneris de daños. Sin embargo, hemos observado que recaen sobre un interés humano, al igual que los que se puede denominar como daños clásicos. También se ha observado que ni en su forma, sus modalidades, ni en su dimensión temporal relativa a su manifestación más o menos dilatada en el tiempo, se distinguen fundamentalmente de los daños clásicos. Como cualquier daño jurídico, son reparables; pero la filosofía que guía su reparación es diferente, a menos que se trate de un elemento medioambiental de titularidad privada. Si no es el caso, el causante del daño tendrá la obligación de repararlo por la única vía legalmente establecida: lo que hemos entendido por restauración. En esto estriba, a nuestra manera de ver, la singularidad de los daños medioambientales.

\section{BIBLIOGRAFÍA}

ALVAREZ VIGARAY, Rafael; «La responsabilidad por daño moral»; Anuario de Derecho Civil, 1996.

BLASCO ESTEVE, Avelino; «Medio ambiente y responsabilidad», en J. ESTEVE PARDO (Coord.); Derecho al medio ambiente y administración local, Madrid, Civitas, 1996.

BUSTO LAGO, José Manuel; La antijuridicidad del daño resarcible en la responsabilidad civil extracontractual, Madrid, Tecnos, 1998.

CANE, Peter; «Indemnización por daños medioambientales»; Anuario de Derecho Civil, t. III, Fasc. III, Jul.- Sept. 2000, pp. 825-848.

CORDERO LOBATO, Encarna; «Derecho de daños y medio ambiente», en ORTEGA ALVAREZ, L.; (Dir.), Lecciones de Derecho del Medio Ambiente, Valladolid, Lex Nova, 1998.

CRAIG, James R., VAUGHAN, David J., SKINNER, Brian J.; Recursos de la tierra y el medio ambiente; $4{ }^{\text {a }}$ ed., Madrid, UNED/PEARSON, 2012.

DE ÁNGEL YAGÜEZ, Ricardo; Algunas previsiones sobre el futuro de la responsabilidad civil, Madrid, Civitas, 1995.

DE LA VEGA GARCIA, Fernando L.,; Responsabilidad civil derivada del producto defectuoso. Un estudio de la Ley 22/1994 en el sistema de responsabilidad civil, Madrid, Civitas, 1998. 
DIEZ-PICAZO GIMENEZ, Gema; "Responsabilidad Civil medioambiental», en VERCHER NOGUERA, A.; DIEZ-PICAZO GIMENEZ, G.; CASTALLON DEL VALLE, M.,; Responsabilidad ambiental: Penal, Civil y Administrativa, Madrid, Ecoiuris, 2003.

EGEA FERNÁNDEZ, Joan; «Relaciones de vecindad, desarrollo industrial y medio ambiente», en ESTEVE PARDO, J.; (Coord.); Derecho al medio ambiente y administración local, Madrid, Civitas, 1996.

ESTEVE PARDO, José; Ley de responsabilidad medioambiental. Comentario sistemático, Madrid, Marcial Pons, 2008.

LASARTE, Carlos; Derecho de obligaciones, t. 2, 15. ${ }^{\text {a }}$ ed., Madrid, Marcial Pons, 2011.

LAZARO CALVO, Trinidad; Derecho internacional del medio ambiente, Barcelona, Atelier, 2005.

LLODRA GRIMALT, Francesca; Lecciones de Derecho Ambiental Civil, Palma, Universitat de les Illes Balears, 2008.

LOPERENA ROTA, Demetrio; Los principios del Derecho ambiental, Madrid, Civitas, 1998.

LOZANO CUTANDA, Blanca; Derecho Ambiental Administrativo, $11 .^{\text {a }}$ ed., Madrid, La Ley, 2010.

MARTIN MATEO, Ramón; Manual de Derecho Ambiental, Cizur Menor, Aranzadi, 2003.

MARTINEZ ESPIN, Pascual; El daño moral contractual en la Ley de propiedad intelectual, Madrid, tecnos, 1996

NAVEIRA ZARRA, Maite María; El resarcimiento del daño en la responsabilidad civil extracontractual, Madrid, Editoriales de Derecho Reunidas, 2006.

REMOND-GOUILLOUD, Martine; Du droit de détruire. Essai sur le droit de l'environnement, Paris, PUF, 1989.

ROJO, Ángel; «El establecimiento comercial»; en MENENDEZ; A. (Dir.); Lecciones de derecho mercantil, 7. ${ }^{\text {a }}$ ed., Cizur Menor, Aranzadi, 2009.

RUDA GONZALEZ, Albert; El daño ecológico puro, Cizur Menor, Thomson Aranzadi, 2008;

SANTOS BRIZ, Jaime; La responsabilidad civil. Derecho sustantivo y Derecho procesal, Madrid, Ed. Montecorvo, 7. ${ }^{\text {ed., }} 1993$.

(C) UNED. Revista de Derecho UNED, núm. 14, 2014 
VIGURI PEREA, Agustín; Globalización y defensa del medio ambiente en el derecho privado: aplicación del principio "quien contamina paga» y régimen de la responsabilidad civil objetiva. Derecho español, europeo, norteamericano y japonés; Madrid, Fundación Registral, Colegio de Registradores de la propiedad y mercantiles de España, 2009.

VOZMEDIANO, Jesús; El hombre insostenible, Sevilla, Universidad de Sevilla, 2012.

YZQUIERDO TOLSADA, Mariano; Sistema de responsabilidad civil, contractual y extracontractual, Madrid, Dykinson, 2001. 